\title{
The Influence of the Gate Geometry on Selected Process Parameters in the High Pressure Die Casting Technology
}

\author{
Jan Majernik $^{1}$, Stefan Gaspar $^{2}$, Martin Podaril ${ }^{1}$, Jan Kolinsky ${ }^{1}$ \\ ${ }^{1}$ Institute of Technology and Business in České Budějovice, Okružní 517/10, 370014 České Budějovice, Czech Republic, \\ E-mail: majernik@mail.vstecb.cz \\ ${ }^{2}$ The Technical University of Košice, Faculty of Manufacturing Technologies with a seat in Prešov, Bayerova 1, 08001 \\ Prešov, Slovak Republic, E-mail: stefan.gaspar@tuke.sk
}

The design of the gating system and the adjustment of the technological parameters of high pressure die casting are closely correlated. Correct connection of the gating system structure and technological parameters will be reflected in the final casting quality. Significant influence on the filling progress of a mold cavity has a gate and its geometry. Within the gate, the final increasing of melt flow velocity arises and determines the filling mode. The contribution is devoted to the influence of the gate height on selected technological parameters. The obtained data are being evaluated and on the basis of the experimental results assessment, the recommendations applicable in the foundry industry are being deduced.

Keywords: high pressure die casting, gate, technological parameters

\section{Introduction}

The gate is a location within the gating system, where the reduction of a sprue cross-section arises before the melt enters into the mold cavity. Reducing the crosssection will increase the velocity of the melt flow. At the same time, the melt flow modulation and determination of the flow character and the filling mode of mold cavity arises.

Within the contribution Issue of Design Gate Dimensions and Experimental Assessment of the Suitability of Analytical Design (Majerník, 2017, in: Key Engineering Materials), the issue of designing the ingate geometry is discussed in detail, where the individual design methods are evaluated in confrontation with the real castings. Monography Influence of Structure Adjustment of Gating System of Casting Mold upon the Quality of Die Cast (Gašpár, 2017, Lüdenscheid: RAM - Verlag) presents the results of a research by a team of authors, where the influence of an gate geometry on the quality parameters of castings is clearly demonstrated.[1] [2]

This contribution builds on the basics of the above mentioned research works. Its dedicated to the influence of the gate geometry on the selected process parameters. Monitored parameters are the filling mode of mold cavity and the time duration of the holding pressure phase. Selected parameters are monitored using the MAGMA5 simulation program version 5.3.1.3.

\section{Characteristics of cast}

Simulations were performed on the flange ingate system of the electric motor shown on Fig. 1.

The setting of technological parameters of the real process was identical with the setting of input parameters in the simulation, as shown in Tab. 1. To maintain the relevant results, these parameters were kept at a constant level.

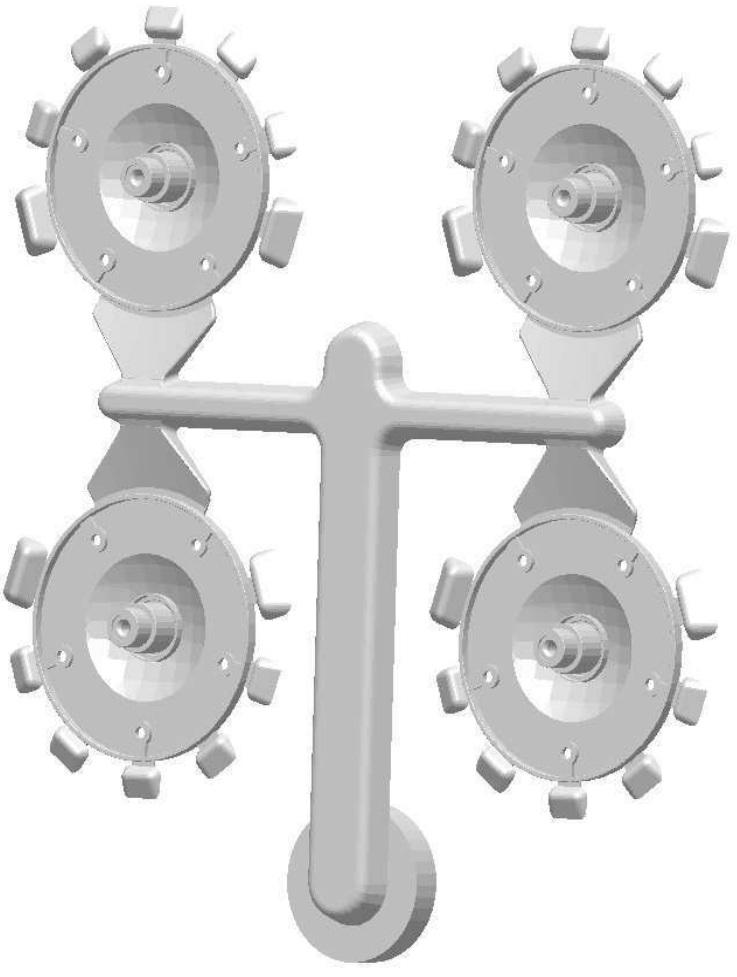

Fig. $13 D$ model of die cast

The location that has been assessed in which the change in selected process parameters was monitored, was chosen in the center of an gate as shown on Fig. 2 .

The setting of technological parameters remained at a constant level. The length of an gate is fixed by the projection methodology of gate connection to the casting with the cylindrical surface.[3] The only variable during the simulation was the height of an gate b. Tab. 2 presents the selected ingate heinghts. 


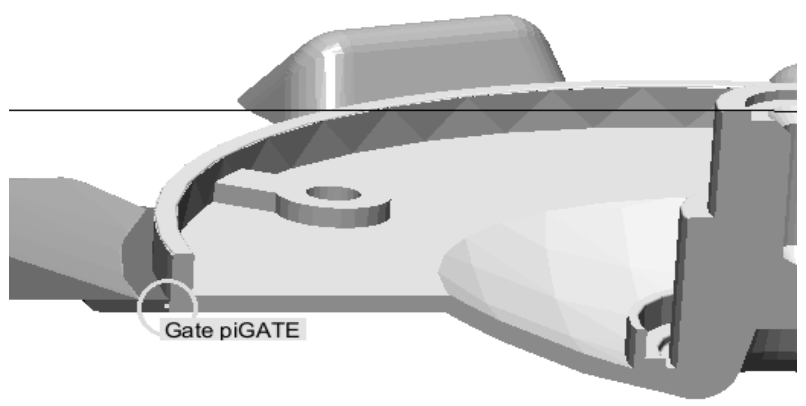

Fig. 2 Assessment location of monitored parameters within the gate
Tab. 1 Basic technological parameters of the casting cycle

\begin{tabular}{|lc|}
\hline \multicolumn{1}{|c|}{ Technological parameters of the casting cycle } \\
\hline Parameter & Value \\
\hline Melt temperature $\left[{ }^{\circ} \mathrm{C}\right]$ & $\mathbf{7 0 8}$ \\
\hline Mold temperature $\left[{ }^{\circ} \mathrm{C}\right]$ & $\mathbf{2 2 0}$ \\
\hline Velocity of the press piston $\left[{\left.\mathrm{m} . \mathrm{s}^{-1}\right]}^{-1}\right]$ & $\mathbf{2 . 9}$ \\
\hline Holding pressure $[\mathrm{MPa}]$ & $\mathbf{2 5}$ \\
\hline The filling time of die cavity mold $[\mathrm{s}]$ & $\mathbf{0 . 0 1 9}$ \\
\hline
\end{tabular}

Tab. 2 Assessed gate heights

\begin{tabular}{|c|c|c|c|c|c|c|}
\hline \multirow{2}{*}{$\begin{array}{c}\text { Ingate height } \\
b[\mathrm{~mm}]\end{array}$} & $b_{1}$ & $b_{2}$ & $b_{3}$ & $b_{4}$ & $b_{5}$ & Ingate length $a[\mathrm{~mm}]$ \\
\hline & 1.25 & 1.03 & 0.92 & 0.82 & 0.75 & \multirow{3}{*}{60.968} \\
\hline \multirow{2}{*}{$\begin{array}{c}\text { Ingate surface } S_{G} \\
{\left[\mathrm{~mm}^{2}\right]}\end{array}$} & $S_{G 1}$ & $S_{G 2}$ & $S_{Z 3}$ & $S_{G 4}$ & $S_{G 5}$ & \\
\hline & 76.210 & 62.797 & 56.090 & 49.994 & 45.726 & \\
\hline
\end{tabular}

\section{Velocity inside the gate $v_{G}$}

The velocity inside the gate is dependent on the pressing speed, which is the speed of the press piston within the filling chamber. According to the value of pressing speed setting, the filling mode of mold cavity and the rate of advancing of the melt are determined. The choice of a suitable pressing speed depends on a number of factors, in particular on the type of casted alloy and the casting dimensions. Assumed velocity of the melt inside the ingate can be derived from the pressing speed using the continuity equation as follows:

$$
S_{P} \cdot v_{P}=S_{G} \cdot v_{G}
$$

$S_{\mathrm{p}}$ - cross-sectional surface of the press piston $\left[\mathrm{m}^{2}\right]$,

$v_{p}$ - velocity of the press piston inside the filling chamber $\left[\mathrm{m} . \mathrm{s}^{-1}\right]$, $\mathrm{mm}^{2}$,

$S_{G}-$ cross-sectional surface of ingate $\left[\mathrm{m}^{2}\right], \mathrm{Sf}=200$

Tab. 3 Velocity values within the assessment location

\begin{tabular}{|c|c|c|c|}
\hline Gate height $b[\mathrm{~mm}]$ & $\begin{array}{c}\text { Gate velocity according } \\
\text { to continuity equation } \\
v_{\text {Gcal }}\left[\mathrm{m}_{\mathrm{s}} \mathrm{s}^{-1}\right]\end{array}$ & $\begin{array}{l}\text { Average gate velocity ac- } \\
\text { cording to simulations } \\
\qquad v_{\text {Gav }}\left[\mathrm{m}_{\mathrm{s}} \mathrm{s}^{-1}\right]\end{array}$ & $\begin{array}{l}\text { Maximum gate velocity } \\
\text { according to simulations } \\
\qquad v_{G}\left[{\left.\mathrm{~m} . \mathrm{s}^{-1}\right]}^{-1}\right.\end{array}$ \\
\hline$b_{1}$ & 36.59 & 37.07 & 40.81 \\
\hline$b_{2}$ & 44.41 & 44.78 & 50.04 \\
\hline$b_{3}$ & 49.72 & 47.99 & 53.23 \\
\hline$b_{4}$ & 55.78 & 55.09 & 60.38 \\
\hline$b_{5}$ & 60.99 & 60.60 & 66.21 \\
\hline
\end{tabular}

As shown in Tab. 3, the velocities vGcal determined on the basis of the equation (2) correspond to the average velocities $v_{G a v}$ determined by the simulation. Considered should be the fact, that the velocities in the start-up phase were also included in the average velocity. In order to better understand the evolution of the velocity inside the gate, a graph showing the increase in the velocity inside
$v_{G}$ - velocity of melt inside the ingate $\left[\mathrm{m} . \mathrm{s}^{-1}\right]$.

Since the investigated gating system is a quadruple mold, the sum of all the surfaces of the ingates connected to the castings must be entered in equation (1). The equation (1) must therefore be modified as follows:

$$
S_{P} \cdot v_{P}=n \cdot S_{G} \cdot v_{G}
$$

$n-$ the number of ingates connected to the castings. [3][4] [5][6]

On the basis of equation (2), the values of predicted velocities inside gates were determined for the examination purposes. These were compared with the velocity values found within the experiments. The maximum and average velocities were measured in the assessment location using the simulations. Only the results deduced from the simulation at the time when the melt flow inside the gate filled $100 \%$ of the surface $S_{Z}$ were considered as relevant. Tab. 3 presents the values of detected velocities. the gate during the filling of a mold cavity was constructed, and its shown as Fig. 3.

As emerge from the Fig. 3, the velocities vG inside the ingate are oscillating above the average values vGav. It can be deduced from this that the values of velocity inside the ingate are always higher than the values calculated on the basis of the continuity equation. 


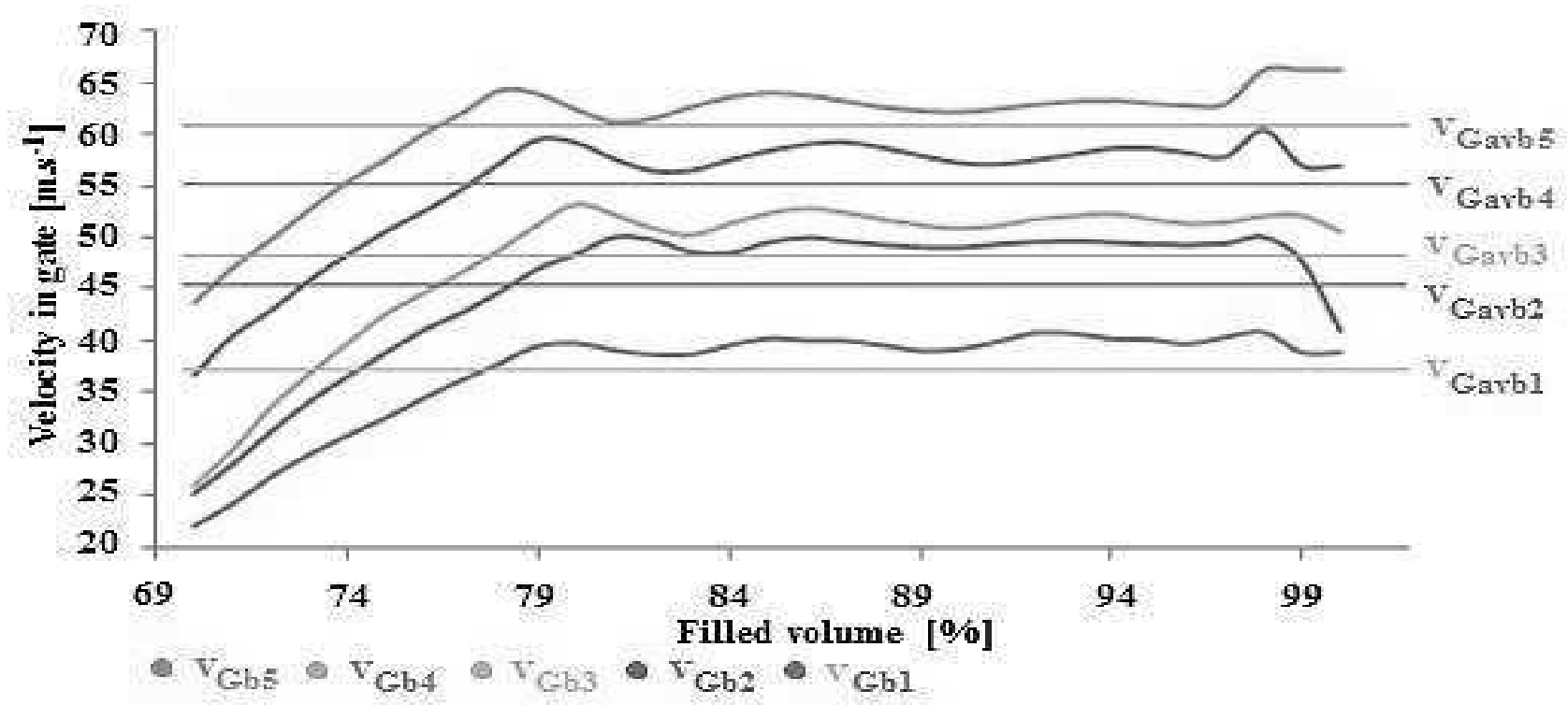

Fig. 3 Development of the velocities during the filling of a mold cavity

\section{The filling mode of cavity mold}

The melt flow within the cavity mold is the first factor determining the casting ,health“. In general, it is required that the melt flow does not cause the vortex flow and thus to the concluded air and gas into the melt volume. Absorption of gases by the melt results in the origination of defects in the form of bubbles and porosity. The filling mode can also be predicted based on the melt velocity inside the gate. In general, we distinguish:

a / low filling speed from 0.6 to $1 \mathrm{~m} \cdot \mathrm{s}^{-1}$, providing a solid laminar filling,

$\mathrm{b} /$ medium filling speed from 1 to $15 \mathrm{~m} \cdot \mathrm{s}^{-1}$, providing a solid turbulent filling,

c / high filling speed above $25 \mathrm{~m} \cdot \mathrm{s}^{-1}$, resulting in a splitting of the integral stream and formation of a dispersive filling. [5][7][8]

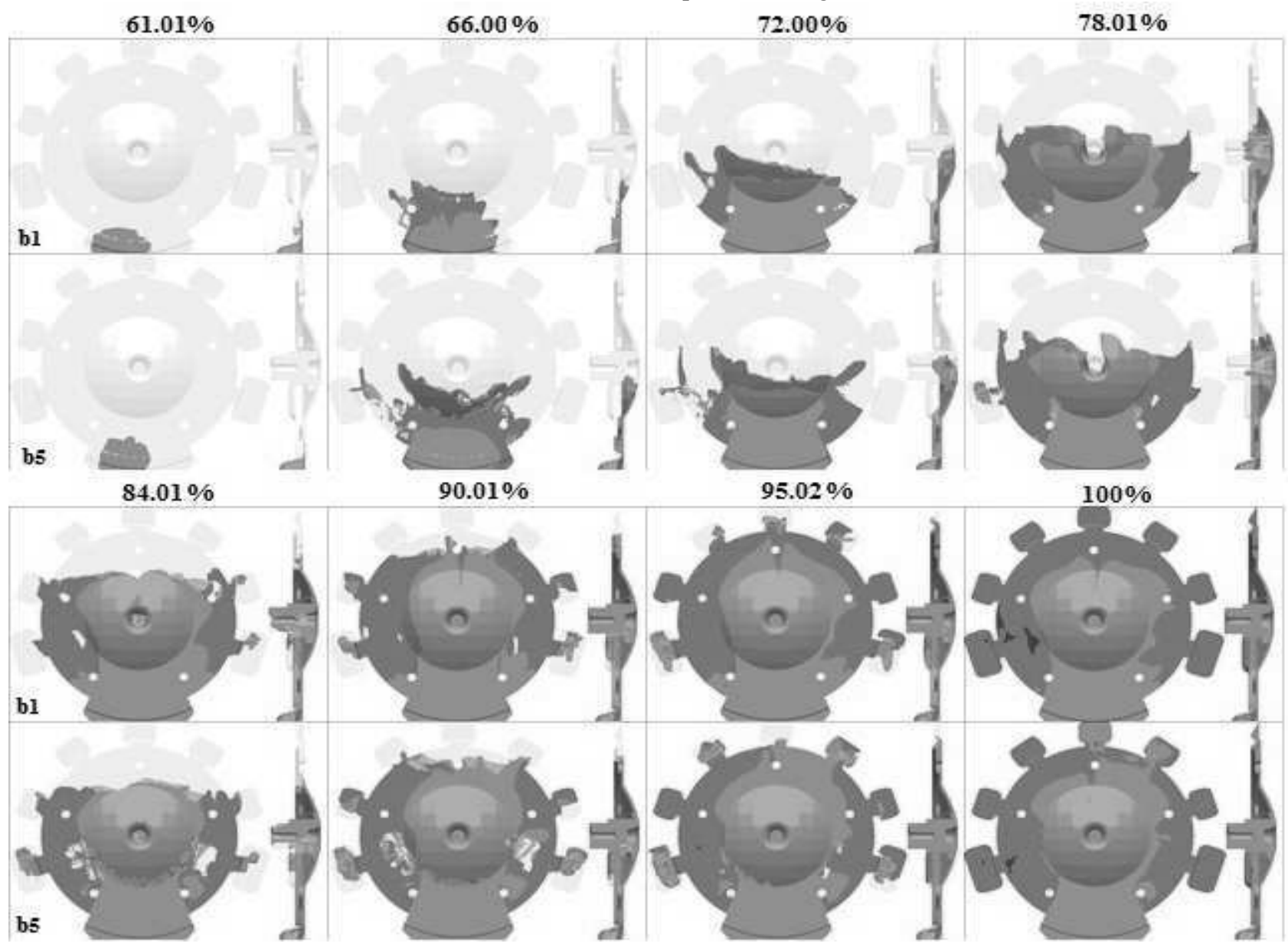

Fig. 4 Formation fo the melt flow 
On the basis of the velocity knowledge inside the gate, it is possible to assume the dispersion flow which forms a dispersion mixture of liquid metal and air when filling the cavity mold. The transition of the melt flow through the mold cavity has been analyzed by simulations. Fig. 4 illustrates the filling of a mold cavity for lateral values of gates heights. The assessment was performed at the time from the intersection of the melt flow through the ingate to $100 \%$ of the filling of the mold cavity.

By evaluating the simulations, it was found that the melt flow pattern is a combination of turbulent, nonplanar-dispersion flow. By decreasing the ingate height the influence of the dispersion by filling the mold cavity was greater. The influence of the velocity is noticeable on the formation of the discontinuity of the melt flow in the area behind the cores. At higher velocity, melt break occur, which allows gas to penetrate into the melt volume. There is a risk of gas congestion, the formation of inhomogeneity and the porosity of the casting.

Tab. 4 Temperature characteristics of the melt

\begin{tabular}{|c|c|c|c|c|c|c|}
\hline $\begin{array}{l}\text { Ingate } \\
\text { height }\end{array}$ & $\begin{array}{c}\text { Liquidus } \\
\text { tempera- } \\
\text { ture } T_{\text {Lig }} \\
{\left[{ }^{\circ} \mathrm{C}\right]} \\
\end{array}$ & $\begin{array}{c}\text { Solidus tem- } \\
\text { perature } \\
T_{\text {Sol }}\left[{ }^{\circ} \mathrm{C}\right]\end{array}$ & $\begin{array}{l}\text { Melt tempe- } \\
\text { rature } T_{A} \\
\quad\left[{ }^{\circ} \mathrm{C}\right]\end{array}$ & $\begin{array}{c}\text { Filling chamber } \\
\text { melt tempera- } \\
\text { ture } T_{A c h}\left[{ }^{\circ} \mathrm{C}\right]\end{array}$ & $\begin{array}{l}\text { Minimum in- } \\
\text { gate tempera- } \\
\text { ture } T_{G \min }\left[{ }^{\circ} \mathrm{C}\right]\end{array}$ & $\begin{array}{l}\text { Maximum in- } \\
\text { gate tempera- } \\
\text { ture } T_{\text {Gmax }}\left[{ }^{\circ} \mathrm{C}\right]\end{array}$ \\
\hline$b_{1}$ & \multirow{5}{*}{590.00} & \multirow{5}{*}{560.00} & \multirow{5}{*}{708.00} & \multirow{5}{*}{615.70} & 602.01 & 608.50 \\
\hline$b_{2}$ & & & & & 601.70 & 609.10 \\
\hline$b_{3}$ & & & & & 600.00 & 609.10 \\
\hline$b_{4}$ & & & & & 600.01 & 610.20 \\
\hline$b_{5}$ & & & & & 599.30 & 610.50 \\
\hline
\end{tabular}

Values listed in Tab. 4 show that the influence of the ingate height on melt is not significant. Higher values of the minimum ingate temperature $\mathrm{T}_{\mathrm{Gmin}}$ at higher ingate heights correspond with temperature capacity of greater volume of metal in gate. Conversely, the maximum temperature $\mathrm{T}_{\mathrm{Gmax}}$ with decreasing gate height was rising. This phenomenon is explicable by the dissipation of the mechanical energy of the flow. Simply put, by reducing the gate cross-section arise to the compression of the flow fibers in the melt and thereby increasing its mutual friction which converts to thermal energy.

\section{Duration of the holding pressure phase $t_{S}$}

Holding pressure is essentially defined as a hydrostatic pressure. Its value must be high in order to overcome the resistance of the crystallising melt in the thin crosssections of the mold cavity and the resistance of the gases bound in the melt volume. It is submiting from the pressing piston through the gating system and gate to the outermost parts of the casting. The pressure stamina is limited by the time interval in which the gate is completely solidificated. The use of larger cross-sectional gates allows the use of holding pressure and feeding of the casting by liquid metal during crystallization over a wider time interval, thereby eliminating shrinkages. [10][11]

Tab. 5 presents the results of the time of complete gate solidification. The length of the holding pressure phase is the time from the complete filling of a mold cavity to the time at which the temperature in gate drops to the solidus

\section{Melt temperature inside the ingate during the filling $T_{G}$}

The melt temperature at the inlet to the mold cavity should be at least $10-20^{\circ} \mathrm{C}$ higher than the temperature at which the melt begins to crystallize, meaning $\mathrm{T}_{\mathrm{G}}>$ $\mathrm{T}_{\text {liq }}+\left(10-20^{\circ}\right)$. If a hot melt is cast into a cold mold which has been insufficiently insulated with a suitable lubricant, the surface layers of the mold will be heavily stressed and the mold will wear out sooner. The low melt temperature on the casting is manifested by the formation of cold joints and map surfaces.[8]

In Tab. 4 the temperature characteristics of alloy EN AC 47100 are shown and declared by the material sheet and simultaneously the temperature ratio evaluated in the casting process and simulated by the software. temperature of the alloy.

Tab. 5 The time of solidification of the gate area

\begin{tabular}{|cc|}
\hline Ingate height $[\mathrm{mm}]$ & Time of solidification $\boldsymbol{t}_{\boldsymbol{S}}[\mathbf{s}]$ \\
\hline $\boldsymbol{b}_{\boldsymbol{1}}$ & 0.354 \\
\hline $\boldsymbol{b}_{2}$ & 0.278 \\
\hline $\boldsymbol{b}_{3}$ & 0.264 \\
\hline $\boldsymbol{b}_{4}$ & 0.207 \\
\hline $\boldsymbol{b}_{5}$ & 0.205 \\
\hline
\end{tabular}

On the basis of simulations performed, on the solidification assessment in the ingate area is apparent that by decreasing the ingate height, the solidification time is reduces. Ingate with lower height solidificates in a shorter time interval, thus shortening the pressure holding time. The difference between the solidification times at the lateral values of ingate heights is $\Delta t=0.149$ s.

\section{Assessment of achieved results}

Analysis of the influence of the ingate height on the change in velocity $v_{G}$

Melted metal flow velocity inside the gate affects the mechanical properties of casting and its surface quality. Higher flow velocity achieves better mechanical properties and lowered porosity. New high-pressure casting machines are capable of developing a velocity up to $100 \mathrm{~m} . \mathrm{s}^{-}$ ${ }^{1}$ but degradation of the mold due to errosive effects 
occurs at aproximately $50 \mathrm{~m} . \mathrm{s}^{-1}$. For this reason the classification of velocity within the range from 50 to $100 \mathrm{~m} . \mathrm{s}^{-}$ ${ }^{1}$ is not recommended. [2][8] [12]

The experiments performed arise that the average melt velocities inside gate correspond to the velocities analytically derived from the piston velocity using the continuity equation. However, considering the graph of velocity development, it has to be also taken into account, that the actual momentary gate velocity during the filling is higher than the average temperature, in average about $6.2 \%$.

\section{Analysis of the mold cavity filling}

Analysing the flow mode and the shape of the melt stream, it is necessary to focus on a number of partial aspects. As can be seen from the simulations for individual gates, with decreasing gate height, the filling mode of the mold cavity is shifted closer to the dispersed character. This allows the gas to be absorbed by the melt which reflects on the castings porosity.

In the melt flow formation, the influence of the melt velocity inside the gate is apparent.During the circumfluence of the cores, the tearing and melt splashes are visible, significantly manifested at higher speeds. Practice requires a solid flow of melt the forehead of which forms a primarily solidificated bark that prevents metal oxidation and gas penetration into the melt. The shaping of the melt stream and the increase of the velocity due to the gate height does not observe this condition not even with one model on the gating system.

Last but not least, it is necessary to take into the account the condition of gradual elimination of owerflows and vents. [2] This aspect is fulfilled for each variation of the gate height, which gives the possibility of removing the concluded gas in the melt at the tear-off in the area behind the cores, as well as the possibility of supplementing the melt in holding pressure phase and maximal elimination of porosity and inhomogeneity in the casting volume.

Analysis of melt temperature inside the ingate during the filling $T_{G}$

Based on simualtions, no significant effect of the gate height on the instantaneous temperature of the melt inside the gate has been demonstrated. Partial changes on the $T_{G \min }$ and $T_{G \max }$ values have been demonstrated, but the time at which these changes were observed is of the order in miliseconds, and the casting process and casting properties have no relevant effect. Changes are explicable by the using of the basics of hydromechanics, by referring to the dissipation of the mechanical energy steam.

Analysis of the time of the holding pressure phase $t_{S}$

As has been shown, the decreasing cross-section of the gate is directly proportional to the change in the heat capacity of the contained within. The result of this is, that gate with lower height will be in solid state within a shorter time interval. This results in a reduction of the holding pressure time on the casting.

The positive influence of the holding pressure on the mechanical and qualitative properties of the casting was experimentally demonstrated. Its high value increases the refill of castings, reduces the volume of the air that is concluded in solidificated castings (porosity) and thus increases the quality of castings (strength, tightness, etc.).

Part of the authors collective dealt also with the possibility of influencing the structure of the eutectic by changing the dimensions of the gate. It has been shown that with the decreasing gate height and thus shortening the time of the holding pressure, the proportion of the $\alpha$ phase is being increased in the surfaces of metallographic cuts, which is reflected in the mechanical properties of the castings.

\section{Conclussion}

The well-designed gating system along with suitably set technological parameters is important with regard to the acquiring of quality indicators of production and, in terms of reducing the rejects during production of castings it possitively affects the economic aspects of production. From the performed experiments it is clear that the geometry of the gate, specifically its height, influences the process parameters of a high pressure die casting technology.

According to the results obtained through simulations, these recommendations have been deduced for designers and technologists in high pressure die casting foundries:

- to select the gate heights in order not to exceed the recommended values of gate melt velocity values with respect to the mold wearing off by the erosive effects of the melt,

- $\quad$ to select the gate cross section so that there is no dispersion in the melt flow. By mixing the gases and melt in the mold cavity, a high porosity is induced,

- $\quad$ to manage the melt flow so that it does not directly hit the obstacles such as cores and protrusions in the mold cavity. Obstacles in the melt flow direction cause the mold cavity filling mode to be changed, melt mixing and subsequent gas conclusion in the metal volume. This increases the proportion of inhomogeneity of the castings. By impacting the shape of the cavity wall and cores the kinetic energy of the melt flow decreases and the temperature conversion and cooling of the heated metal occurs, which can result into non-refilling.

- to place the gate so that when the cavity is filling, the individual venting components were gradually eliminated with respect to the outermost venting locations retain the functionality even during the last filling phase. By gradually filling of the mold cavity we predict the formation of porosity and bubbles,

- $\quad$ higher values of the gate height result in a longer solidification time of the ingate which results into longer effect of the holding pressure on casting and therefore to a better reduction of the microporosity and shrinkages arising from the metal shrinkage during the solidification.

\section{Acknowledgement}

This paper has been prepared within the project $V E G A$ 1/0041/16. 


\section{References}

[1] MAJERNÍK, J., KARKOVÁ, M., KMEC, J. (2017). Issue of Design Gate Dimensions and Experimental Assessment of the Suitability of Analytical Design. Key Eng. Mater., 2017, vol. 756, p. 142-148. ISSN 1662-9795.

[2] GAŠPÁR, ড̌., PAŠKO, J., MAJERNÍK, J. (2017). Influence of Structure Adjustment of Gating System of Casting Mold upon the Quality of Die Cast. 1st ed. Lüdenscheid: RAM - Verlag, 2017. 82 p. ISBN 978-3-942303-47-7.

[3] ČSN 228601. Formy tlakové licí. Zásady pro navrhování.. Praha: Vydavatelství Úřadu pro normalizaci a měření, 1984. 32 p.

[4] MAJERNÍK, J., KMEC, J., KARKOVÁ, M. (2017). Analysis of the Impact of the Construction of a Gate on the Macroscopic Structure of a Casting and Its Influence on the Mechanical Properties of Castings. Manufacturing Technology, 2017, vol. 17, no. 1, p. 62-66. ISSN 1213-2489.

[5] PAŠKO, J., GAŠPÁR, Š. (2014). Technological factors of die casting. 1st ed. Lüdenscheid: RAM - Verlag, 2014. 93 p. ISBN ISBN 978-3-94230325-5.

[6] PAŠKO, J. (2010). Die Casting Plunger Pressing Velocity and Analysis of Its Influence on a Permanent Deformation Value of a Casting Made from an ENAC 47100 Alloy. Manufacturing Technology, 2010, vol. 10, p. 23-26. ISSN 1213-2489.
[7] STUNOVÁ, B.; NOVOTNÝ, F.; PROKOP, J. (2010). Computer Tomography in Comparison with Other Testing Methods Used for the Leakage Testing of HPDC Parts. Manufacturing Technology 2010, 10, 29-34. ISSN 1213-2489.

[8] MALIK, J. (2013). Technológia tlakového liatia zliatin hliníka. Košice: Technická univerzita v Košiciach, 2013. 274 s. ISBN 978-80-553-1450-1

[9] PETI, F., GRAMA, L., SOLOVASTRU, L., CORB, C. (2010). Studies concerning the design of the runner, gate and venting systems in the case of the high pressure die casting technology. In: Fascicle of Management and Technological Engineering. Vol. 29, No. 9/2010, p. 3177-3183, ISSN 1583-0691.

[10] POKORNÝ, Z., STUDENÝ, Z., POSPÍCHAL, M., HRUBÝ, V., JOSKA, Z. (2015). Characteristics of Plasma nitrided Layers. Manufacturing Technology, 2015, vol. 15, no. 3, p. 403-409. ISSN 1213-2489.

[11] BOLIBRUCHOVÁ, D., RICHTÁRECH, L. (2013). Study of the gas content in aluminum alloys. Manufacturing Technology, 2013, vol. 13, no. 1, p. 14-20. ISSN 1213-2489.

[12] MACHUTA, J., NOVÁ, I., KEJZLAR, P. (2017). Structure and Mechanical Properties of Aluminium Alloys AlSi10 and AlSi5Mg. Manufacturing Technology, 2017, vol. 17, no. 5, p. 772-777. ISSN 1213-2489. 